Article

\title{
Comparison of Usage and Influencing Factors between Governmental Public Bicycles and Dockless Bicycles in Linfen City, China
}

\author{
Xiaojia Guo ${ }^{1,2} \mathbb{D}$, Chengpeng Lu ${ }^{3, *} \mathbb{C}$, Dongqi Sun ${ }^{2}$, Yexin Gao ${ }^{1}$ and Bing Xue ${ }^{4}(\mathbb{D}$ \\ 1 College of Geographic Science, Shanxi Normal University, Linfen 041000, China; guoxj@sxnu.edu.cn (X.G.); \\ gaoyexin@stu.sxnu.edu.cn (Y.G.) \\ 2 Institute of Geographic Sciences and Natural Resources Research, Chinese Academy of Sciences, \\ Beijing 100101, China; sundq@igsnrr.ac.cn \\ 3 Institute of County Economic Development \& Rural Revitalization Strategy, Lanzhou University, \\ Lanzhou 730000, China \\ 4 Institute of Applied Ecology, Chinese Academy of Sciences, Shenyang 110016, China; xuebing@iae.ac.cn \\ * Correspondence: lcp@lzu.edu.cn
}

check for updates

Citation: Guo, X.; Lu, C.; Sun, D.; Gao, Y.; Xue, B. Comparison of Usage and Influencing Factors between Governmental Public Bicycles and Dockless Bicycles in Linfen City, China. Sustainability 2021, 13, 6890. https://doi.org/10.3390/su13126890

Academic Editor: Adriana Del Borghi

Received: 8 May 2021

Accepted: 14 June 2021

Published: 18 June 2021

Publisher's Note: MDPI stays neutral with regard to jurisdictional claims in published maps and institutional affiliations.

Copyright: (c) 2021 by the authors. Licensee MDPI, Basel, Switzerland. This article is an open access article distributed under the terms and conditions of the Creative Commons Attribution (CC BY) license (https:/ / creativecommons.org/licenses/by/ $4.0 /)$.

\begin{abstract}
Automobile traffic has shifted the use of bicycles in many developed regions to being mainly for sport, recreation and commuting. Due to the desire to mitigate the impacts of climate change and alleviate traffic jams, bicycle sharing is booming in China. Governmental public bicycles and dockless bicycles are the main types of bicycle sharing in China, each with different types of management and pricing. Field research has found that many bicycle sharing networks are idle and wasteful, and thus we investigated which type is more popular and suitable for Chinese cities. This research comparatively analyzes the application of governmental public bicycles and dockless bicycles, mainly focusing on the cycling destination, cycling frequency, and cycling factors, taking Linfen City as an example. The results show that: (1) The purpose is different between governmental public bicycles and dockless bicycles. On the one hand, the aim of riding a governmental public bicycle to work represents the largest proportion at about $29 \%$, mainly because of the fixed route of travel, and the fact that the fixed placement of governmental public bicycles makes them more available compared to the random arbitrariness of dockless bicycles. On the other hand, the aim of riding a dockless bicycle for entertainment accounts for the largest proportion, at about 34\%, mainly due to the ease of borrowing and returning a bike, and mobile payment. (2) In terms of frequency, the public's choice of riding a dockless bicycle or a governmental public bicycle has no essential difference, given that there are only two options for citizens in Linfen. (3) The response to the two kinds of bicycle sharing is different; the governmental public bicycle has the advantage of lower cost, but the dockless bicycle has more advantages in the procedure of borrowing and returning the bicycle.
\end{abstract}

Keywords: bicycle sharing; questionnaire survey; influencing factors; comparative analysis; China

\section{Introduction}

With the important role of cities in national development, it has been found that the modalities of urban development and management are not only of instantaneous and direct significance, but also have multiple long-term strategic impacts on urban development [1] There is no doubt that the growth of cities and their populations causes a series of problems, such as aggravating acute climate change, widening the gap between rich and poor, and leading to more serious traffic jams. Smart city development is an inevitable choice, consistent with the development trends of the current time. As the reduction in urban automobile traffic is crucial to mitigating the impacts of climate change, promoting urban public transport is becoming increasingly attractive [2]. With the growing travel demands 
of residents, the number of private cars has increased dramatically, playing an important role in people's daily lives [3]. According to statistics from the Ministry of Public Security of China, the ownership of personal vehicles in the country has risen from 18 million in 2005 to 240 million in 2018, thus leading to traffic congestion, local air and noise pollution, climate change, obesity and chronic diseases, road injuries and casualties, reduction in outdoor activities, and loss of social participation [4-7]. The importance of green travel, such as public transport, cycling, or walking, is gradually being recognized [8-10]. However, public transport cannot meet the needs of "the last mile" [11]. In order to solve the problem of short-distance travel, local governments provide public bicycles in many cities, and some enterprises also provide dockless bicycle services for citizens, such as Ofo, Mobike, Didi, etc. Therefore, bicycle sharing is changing citizens' travel behavior, and it will be part of a sound toolbox that helps to form a new travel ethos [12]. Goals related to bicycle sharing programs include increasing usage and mobility options for bicycles, improving the connection of the first and last mile to other travel modes, reducing traffic jams and energy consumption, reducing environment effects, and improving public health [13-16].

At present, there are two main types of bicycle sharing, one being governmental public bicycles with piles, and the other being dockless bicycles operated by enterprises [17]. The former appeared earlier, generally funded by the government to build car rental points and set up a public bicycle operation system [18]. By the end of 2016, more than 400 cities and counties in China were equipped with public bicycle systems with 890,000 governmental public bicycles installed, and the country had the highest number of governmental public bicycles in the world [19]. Compared with governmental public bicycles, dockless bicycles appeared later, but developed faster. By the end of August 2019, there were 19.5 million dockless bicycles covering 360 cities in the country, with more than 300 million registered users. Because of the rapid market expansion efficiency of dockless bicycles, citizens tend to choose them once experiencing their speed and convenience, while governmental public bicycles have been widely abandoned and have a high idle rate [20]. However, after a short period of brilliance, large-scale dockless bicycles have often exceeded the capacity of the city and brought challenges to city management [21], and 45 bicycle cemeteries have appeared in nearly 30 large cities [22].

Bicycle sharing, as a shared mode of transportation, has attracted more and more attention in recent years. Foreign scholars have mainly focused on the service characteristics of public bicycle systems. Efthymiou and Antoniou (2017) [23] used a latent variable model to study the impact of a crisis on public transport users' satisfaction and demand. Hwan Lee et al. (2015) [24] analyzed the influence of the neighborhood environment on residents' use of public bicycles by constructing a hierarchical linear model. Bordagaray et al. (2015) [25] used a calibrated ordered probability model to study the quality of service perceived by public bicycle program users. Wafic et al. (2017) [26] used year-round historical travel data to analyze factors affecting the number of passengers using bicycle sharing in Toronto. Levy et al. (2019) [27] used an integrated model to analyze the Tel Aviv bike sharing system and corresponding GTFS data, and they found that cycling activities were not well-balanced and that cycling behaviors were strongly associated with the length of trips. Radzimski and Dzięcielski (2021) [28] analyzed the contribution of bike sharing to public transport, and their results showed that the frequency of public transport was significantly related to the number of bike sharing trips, with a positive impact on shortand medium-distance trips, whereas no relationship was found for long-distance travel. Kevin B et al. (2018) [29] used grounded theory to illustrate how individuals use and maintain bicycle commuting. Domestic scholars have mainly focused on site planning and construction, and user satisfaction with public bicycles. Luo et al. (2018) [30], taking the Qiaobei area of Nanjing as the study object, designed a method to examine the influence of built environment attributes on bicycle usage with internet open data. Qian et al. (2014) [31] constructed a structural equation hypothesis model based on exploratory factor analysis and analyzed the factors affecting Suzhou public bicycle satisfaction. Wan et al. (2018) [32] used on-the-spot investigation, an observation method, and a questionnaire survey method 
to study the influencing factors of using sharing bicycle travel in recreation. Li et al. (2018) [33] conducted a survey to study the factors affecting users' behaviors in a freefloating bike sharing (FFBS) system in Jiangsu province, China, and found that the public used FFBS in short-distance trips, and especially for commuting and schooling, which coincided with the rush-hour in urban areas; factors such as education, daily transportation cost, the benefit to users' health, and the convenience of picking up and parking procedure have a positive impact on the usage of FFBS. On the basis of analyzing the similarities and differences between governmental public bicycles and dockless bicycles in China, Liang (2017) [34] put forward the idea of the two systems complementing and integrating with each other. Lazarus et al. (2020) [35] focused on understanding how docked bike sharing and dockless e-bike sharing models complement and compete with respect to user travel behaviors, and results show that dockless e-bike trips were longer in distance and duration than docked trips, and bike rack density was a significant positive factor for a rider. Long et al. (2017) [36] compared the difference among dockless bicycles, governmental public bicycles and private bicycles through field investigation and data analysis in the core area of Xizhimen transportation hub, and summarized the use characteristics and application improvement space of sharing bicycles. Chen et al. (2020) [37] tried to explore the relationship between users and use frequency of the services for the station-based bike sharing system (SBS) with docks and dockless free-floating bike sharing systems (FBS), and results showed that SBS and FBS had a similar user structure but different factors influenced use frequency. Li et al. (2019) [38] tried to dig out the differences of travel behavior among private bicycle (PB), public bicycle sharing (PBS), and free-floating bike sharing (FFBS), and applied multinomial logistic model to explore the influential factors, results showed that the travel distance in gender, travel purpose in geographic space and bicycle users' preferences different among the three bike system, FFBS and PB were more favored by long-distance exercise while PBS was more preferable in fixed demand. Ji et al. (2020) [39] tried to compare usage regularity and determinants between docked and dockless bike sharing systems, and revealed that travel-behavior and built-environment factors would influence the usage regularity of the both bike sharing systems.

To sum up, different scholars at various times in history have placed more or less attention to the creation and maintenance of public bicycle as it serves as an effective countermeasure for mitigating the impact of climate change and alleviating traffic jam. Due to the different national system, population, historical and cultural background, the research content of domestic and foreign scholars also varies slightly. Foreign scholars mainly focus on the service characteristics of public bicycle systems, such as Efthymiou and Antoniou (2017) [23], Hwan Lee et al. (2015) [24], Bordagaray et al. (2015) [25], Wafic et al. (2017) [26], and Levy et al. (2019) [27] studied the public bicycle operation and service management system from different perspectives. Domestic scholars mainly focus on the site planning and construction, and satisfaction of public bicycles, and usually tried to found the factors affecting the number of passengers and public satisfaction and the contribution of bike-sharing to public transport in the mixed research of sharing bicycle, and revealed the geographical differences and the built-environment impact on the usage of bike-sharing systems. Thanks to the rapid development of information technology, the types and operation modes of sharing bicycles have become diversified, some scholars switched to comparatively study between the governmental public bicycle and dockless bicycle systems. However, because of the huge passengers in a crowed metropolitan environment, the comparative studies usually focus on developed region and cities $[40,41]$, such as San Francisco [35], Beijing [36], Hangzhou [37], Kunming [38], and Nanjing City [39]. On the contrary, there are fewer studies that tested within the context of small and medium-sized cities and developing regions [42], despite the fact that the number of such scale cities account for a third of the total number of cities in China. Therefore, it is necessary to study the situation of bicycle sharing in cities of these scale.

Therefore, this paper takes Linfen City, one of such ordinary small cities in a developing region, as a research region, and tries to collect data through questionnaires, to 
compare the use of dockless bicycle and governmental bike sharing systems, and find out the problems during the implementation of bicycle sharing. The primary aim of this study is to comparatively analyze the use of governmental public bicycles and dockless bicycles in a developing area. So far, most studies on bicycle sharing have focused on large cities, such as Beijing, Shanghai, Hangzhou, and Wuhan, however the study of bicycle sharing in large cities may not have the same findings compared to a study conducted in a developing area. This is a key reason that we have researched bicycle riding destination, cycling frequency and cycling factors in Linfen city, a small city which is representative of one third of such scale Chinese cities. The travel frequency of dockless bicycles in Beijing, Shanghai, Hangzhou, and other large cities is higher than that of governmental public bicycles. However, the survey results of Linfen City show that there is no essential difference in the frequency of use between governmental public bicycles and dockless bicycles in small cities. Both types of bicycle sharing have played a positive role in public traffic; users like the lower charge of the government public bicycle but also prefer the convenience of dockless bicycles procedure of borrowing and returning. Based on this, it is hoped to give suggestions for public bicycle development in the same scale cities in developing regions.

\section{Study Area and Methods}

\subsection{Study Area}

Linfen City is located in the southwest of Shanxi Province in central China, (Figure 1). The climate between the semi-arid and semi-humid monsoon climate, with the annual average temperature of $9-12.9^{\circ} \mathrm{C}$, and the annual average sunshine hours about $1748.4-2512.6 \mathrm{~h}$, which is suitable for cycling. At the beginning, Linfen City completed 79 public bicycle station, put in more than 2000 governmental public bicycles. However, as a small city in the developing region, there is only one sharing bicycle company, i.e., Mobike. The Mobike company has distributed 10,000 dockless bicycles, which can meet more than 100,000 citizens' daily ride, and can reduce carbon dioxide emissions by more than 5000 tons per year.

\subsection{Questionnaire Design}

In order to analyze the usage regularity and its influencing factors between governmental public bicycles and dockless bicycles in Linfen City, this questionnaire consists of two parts. The first part is the basic information of the interviewee, mainly including gender, age, occupation type, income, education level, and riding ability. The second part includes six questions, including the frequency of cycling, cycling purpose, bicycle type, selected reason, existing problems, and future outlook, as follows:

Question 1. Your gender. Answer: [A male]; [B female];

Question 2. Your age. Answer: [A <= 17]; [B 18-29]; [C 30-49]; [D >= 50];

Question 3. The type of your occupation. Answer: [A students]; [B employees of government]; [C employees of enterprises and institutions]; [D liberal professions]; [E others];

Question 4. Your month income. Answer: [A <2000 RMB]; [B 2000-4000 RMB]; [C 4000-6000 RMB]; [D >6000 RMB];

Question 5. Your education. Answer: [A primary school and below]; [B middle school]; [C college]; [D graduate and above];

Question 6. Can you could ride bike? Answer: [A yes]; [B no (if you choose this, just need to answer the Question 11 and 12];

Question 7. How often you ride a bike. Answer: [A over 5 times per week]; [B 3-4 times per week]; [C 1-2 times per week]; [D 1 time or less];

Question 8. The purpose of your bike trip. Answer: [A commuting]; [B schooling]; [C Leisure and Entertainment]; [D exercise]; [E other];

Question 9. Usually, which of the following bikes you choose to ride? Answer: [A private bicycle]; [B governmental public bicycle]; [C dockless bicycle]; 
Question 10. Reasons for choosing this bike. Answer: [A simple procedures]; [B quick returning]; [C cheap price]; [D cycling comfort]; [E large range of application]; [F follow the trend]; [G green and environment friendly]; [H other];

Question 11. Which is the most serious problem with sharing bikes. Answer: [A lack of social morality (artificial destruction, unauthorized locking)]; [B waste of resources (lots of bikes left idle)]; [C safety issues (no special bicycle lane, motor and non-motorized lane mixed, rain and snow weather)]; [D other];

Question 12. Your views on the future prospects of sharing bikes. Answer: [A optimistic, that shared bikes will run smoothly]; [B pessimism, too many problems to be sustainable development]; [C indifferent].

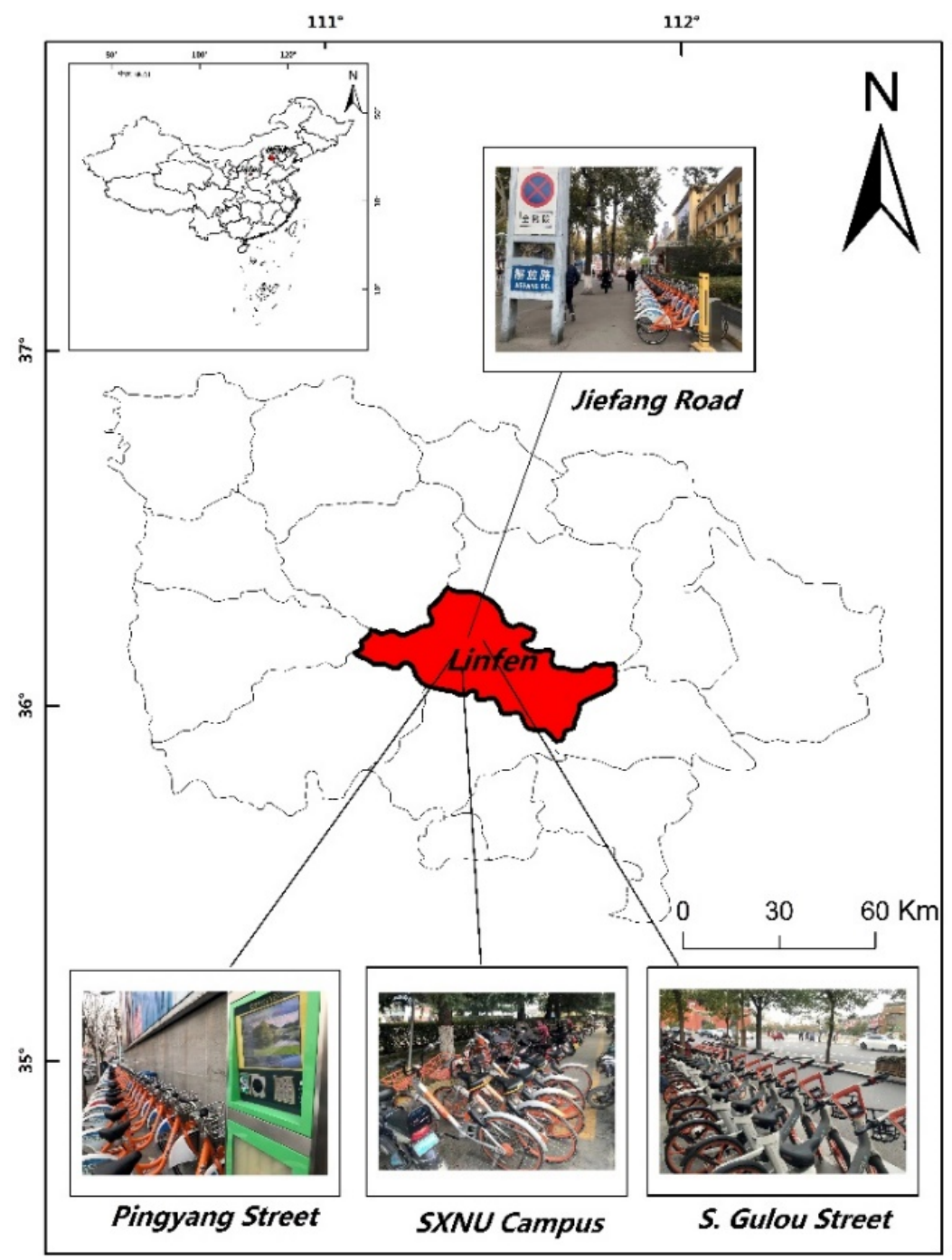

Figure 1. The map of Linfen City.

\subsection{Questionnaire Collection}

This questionnaire is mainly carried out online and offline during December 2018. On the one hand, we will produce a questionnaire about public bicycle trips based on snowball sampling, on the other hand, we conducted paper questionnaires and collected the finished samples from the residents in urban area of Linfen City. Questionnaires are sent to areas with dense populations to ensure that respondents are users of public transportation. A total of 480 questionnaires were distributed and 459 valid questionnaires were returned, with an effective rate of $95.8 \%$. Through data cleaning, data entry, and other preprocessing, 21 incomplete surveys have been filtered out. SPSS17.0 software is used to preprocess 
individual missing data in the questionnaire, and the original data are supplemented by the mean substitution method. After data cleaning and data entry, the individual characteristics of the respondents were described and analyzed, see Table 1. As far as gender is concerned, it is found that females account for about $56 \%$ of the study population. The study group was concentrated between 18 and 49 years old, representing $96.73 \%$ of the study population, while very few respondents were $0-17$ years old or older than 50 years old, which may be related to the Linfen City public bicycle borrowing card system, which only allows applicants between the ages of 16 and 65 . The group with monthly income less than $\$ 314$ accounted for $45.75 \%$ of the study population, the group with monthly income of $\$ 314-784$ accounted for $42.48 \%$, the two groups accounted for $88.23 \%$ of all sharing bicycle users, which indicates that sharing bicycles are popular in low income groups. About $44 \%$ of users choose to use a sharing bicycle to go to their office or school; obviously, this echoes the government's efforts to promote bicycle sharing, in order to reduce air pollution and traffic congestion. In terms of frequency of use, the proportion of occasional use is up to $70 \%$, and more than $12 \%$ of interviews used public bicycles every day, indicating that the implementation of public bicycles has won the support of some citizens in Linfen City.

Table 1. Individual characteristic statistics of the respondents.

\begin{tabular}{|c|c|c|c|}
\hline Item & Category & Frequency & Percentage \\
\hline \multirow{2}{*}{ Gender } & male & 202 & 44 \\
\hline & female & 257 & 56 \\
\hline \multirow{4}{*}{ Age } & $\leq 17$ & 10 & 2.19 \\
\hline & $1 \overline{8}-29$ & 276 & 60.23 \\
\hline & $30-49$ & 168 & 36.5 \\
\hline & $\geq 50$ & 5 & 1.08 \\
\hline \multirow{5}{*}{ Occupation } & students & 247 & 53.8 \\
\hline & employees of government & 64 & 14.04 \\
\hline & $\begin{array}{l}\text { employees of enterprises } \\
\text { and institutions }\end{array}$ & 27 & 5.85 \\
\hline & liberal professions & 62 & 13.45 \\
\hline & others & 59 & 12.87 \\
\hline \multirow{4}{*}{ Income } & $<2000 \mathrm{RMB}$ & 210 & 45.75 \\
\hline & 2000-4000 RMB & 195 & 42.48 \\
\hline & 4000-6000 RMB & 33 & 7.23 \\
\hline & $>6000 \mathrm{RMB}$ & 21 & 4.54 \\
\hline \multirow{4}{*}{ Education } & primary school and below & 14 & 3.05 \\
\hline & middle school & 142 & 30.94 \\
\hline & college & 209 & 45.53 \\
\hline & graduate and above & 94 & 20.48 \\
\hline
\end{tabular}

This study applies the KMO test and Bartlett spherical test to verify the factors affecting the use of urban bicycles in Linfen City. The KMO test coefficient is 0.554 greater than 0.5 , and the Bartlett spherical test $p$ value is 0.001 less than 0.05 , which indicates that the correlation between variables is very strong, and factor analysis can be done. The principal component analysis is used to extract the 10 factors that affect the sharing bicycle in Linfen city, and then the maximum balance value method is used to rotate the factors, and the variables after rotation are classified. Based on this, using the four extracted variables as independent variables, the model of influencing factors was constructed.

\section{Results and Analysis}

\subsection{Comparative Analysis of Ride Purpose}

Bicycles, on the one hand, reduce the frequency of use of motor vehicles, effectively alleviate urban traffic pressure and reduce urban air pollution to a certain extent $[19,20,43]$. On the other hand, they increase the public's chances of doing aerobic exercise, which is 
conducive to good health. The survey mainly investigated the purpose of governmental public bicycles and dockless bicycles (here it is Mobike) including commuting, traveling to school, entertainment, physical exercise, and other aspects. According to the investigation (Figure 2), with regard to governmental public bicycles, the proportion of use for going to work is the largest segment, at about $29 \%$, which is consistent with the research conclusions of Chen et al. (2020) [37] about Hangzhou bike sharing, and the research results of Li et al. (2019) [38] about Kunming bike sharing. Probably because of the fixed travel routes, the fixed distribution of public bicycles station made it higher available for the passenger than the random placed dockless bicycles [35]. Using governmental public bicycles for entertainment accounts for $26 \%$, while using governmental public bicycles for school, exercise, and other purposes is basically the same, $23 \%, 23 \%$, and $22 \%$, respectively. As far as dockless bicycles were concerned, the proportion of entertainment was the largest, which accounted for $34 \%$, mainly due to the convenience of mobile payment and simple procedure for dockless bicycles [32]. The purpose of going to work and exercise by dockless bicycle have the same proportion of $25 \%$, while traveling to school accounted for $16 \%$.

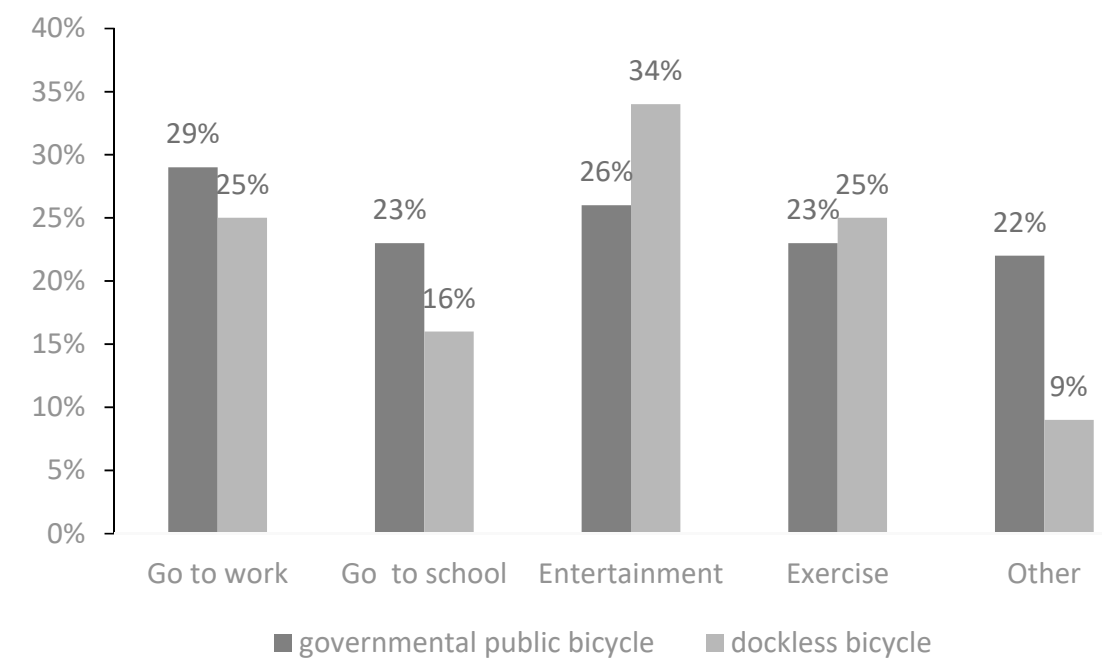

Figure 2. The purpose of cycling.

\subsection{Comparative Analysis of Riding Frequency}

After a descriptive statistical analysis of the riding frequency in the SPSS (Table 2), among the respondents, the frequency of using the governmental public bicycle is 2.8 , and the frequency of using the dockless bicycle is 2.76 , the mean of the two both are more than the mean of the frequency of private bicycle, 2.61, which indicates that Linfen citizens often use sharing bicycles to travel, which is very useful to solve the "first/last mile" problem [11]. The standard deviation of the frequency of travel using governmental public bicycles and dockless bicycles is 1.325 and 1.149, respectively. The gap between the two is very small, which shows that there is no essential difference between public governmental public bicycle and dockless bicycle. This is most likely because, when using a sharing bicycle, Linfen citizens only have two choices, the governmental bicycles or Mobike.

Table 2. Analysis of riding frequency characteristics.

\begin{tabular}{cccccc}
\hline Item & Mean & $\begin{array}{c}\text { Standard } \\
\text { Deviation }\end{array}$ & Median & Minimum & Maximum \\
\hline $\begin{array}{c}\text { Use private } \\
\text { bicycle frequency }\end{array}$ & 2.61 & 1.643 & 3 & 1 & 4 \\
$\begin{array}{c}\text { Use governmental public } \\
\text { bicycle frequency } \\
\text { Usse dockless }\end{array}$ & 2.8 & 1.325 & 3 & 1 & 1 \\
bicycle frequency & 2.76 & 1.149 & 3 & & 4 \\
\hline
\end{tabular}




\subsection{Affect Factor Analysis and Model Construction}

According to the results of SPSS's independent sample inspection of the factors affecting governmental public bicycles and dockless bicycles (Table 3), there are significant differences between governmental public bicycles and dockless bicycles in terms of procedures, convenient transportation, usage fees, and herd mentality. In particular, there are obvious deviations in the three items of procedures, convenient transportation, usage fees. In addition, there were insufficient differences between governmental public bicycles and dockless bicycles in terms of cycling comfort, scope of application, environmental protection, social morality, waste of resources, and safety issues.

Table 3. Independent sample $t$ test for indicators of public bicycles and commercial sharing bicycles.

\begin{tabular}{|c|c|c|c|c|c|c|c|c|}
\hline & \multirow{2}{*}{ Item } & \multicolumn{2}{|c|}{$\begin{array}{c}\text { Levene Test of } \\
\text { Variance Equation }\end{array}$} & \multicolumn{5}{|c|}{$t$-Test of Mean Equation } \\
\hline & & $\mathbf{F}$ & Sig & $\mathbf{t}$ & df & $\begin{array}{l}\text { Sig. } \\
\text { Bilateral }\end{array}$ & $\begin{array}{c}\text { Mean } \\
\text { Difference }\end{array}$ & $\begin{array}{c}\text { Standard } \\
\text { Difference }\end{array}$ \\
\hline \multirow{2}{*}{$\begin{array}{l}\text { Handle } \\
\text { procedures }\end{array}$} & $\begin{array}{c}\text { Assume that the } \\
\text { variances are equal }\end{array}$ & 126.771 & 0.000 & -7.285 & 0.122 & 0.000 & -0.563 & 0.077 \\
\hline & $\begin{array}{l}\text { Assume that the } \\
\text { variances are not equal }\end{array}$ & & & -8.499 & 120.135 & 0.000 & -0.563 & 0.066 \\
\hline \multirow{2}{*}{$\begin{array}{c}\text { Bicycle } \\
\text { convenience }\end{array}$} & $\begin{array}{c}\text { Assume that the } \\
\text { variances are equal }\end{array}$ & 39.892 & 0.000 & -4.894 & 122 & 0.000 & -0.416 & 0.085 \\
\hline & $\begin{array}{l}\text { Assume that the } \\
\text { variances are not equal }\end{array}$ & & & -5.225 & 113.127 & 0.000 & -0.416 & 0.080 \\
\hline \multirow{2}{*}{ Use fee } & $\begin{array}{c}\text { Assume that the } \\
\text { variances are equal }\end{array}$ & 18.178 & 0.000 & -1.393 & 122 & 0.055 & -0.163 & 0.084 \\
\hline & $\begin{array}{l}\text { Assume that the } \\
\text { variances are not equal }\end{array}$ & & & -2.028 & 108.476 & 0.045 & -0.163 & 0.081 \\
\hline \multirow{2}{*}{ Cycling comfort } & $\begin{array}{c}\text { Assume that the } \\
\text { variances are equal }\end{array}$ & 6.403 & 0.013 & 1.414 & 122 & 0.160 & 0.122 & 0.086 \\
\hline & $\begin{array}{l}\text { Assume that the } \\
\text { variances are not equal }\end{array}$ & & & 1.378 & 87.074 & 0.172 & 0.122 & 0.089 \\
\hline \multirow{2}{*}{$\begin{array}{l}\text { Scope of } \\
\text { application }\end{array}$} & $\begin{array}{c}\text { Assume that the } \\
\text { variances are equal }\end{array}$ & 0.101 & 0.751 & 0.160 & 122 & 0.873 & 0.013 & 0.084 \\
\hline & $\begin{array}{l}\text { Assume that the } \\
\text { variances are not equal }\end{array}$ & & & 0.159 & 93.029 & 0.874 & 0.013 & 0.084 \\
\hline \multirow{2}{*}{$\begin{array}{l}\text { Congregational } \\
\text { psychology }\end{array}$} & $\begin{array}{c}\text { Assume that the } \\
\text { variances are equal }\end{array}$ & 29.544 & 0.000 & -2.361 & 122 & 0.020 & -0.149 & 0.063 \\
\hline & $\begin{array}{l}\text { Assume that the } \\
\text { variances are not equal }\end{array}$ & & & -2.744 & 120.454 & 0.007 & -0.149 & 0.054 \\
\hline \multirow{2}{*}{ Green } & $\begin{array}{l}\text { Assume that the } \\
\text { variances are equal }\end{array}$ & 9.557 & 0.002 & -1.744 & 122 & 0.084 & -0.148 & 0.085 \\
\hline & $\begin{array}{l}\text { Assume that the } \\
\text { variances are not equal }\end{array}$ & & & -1.685 & 84.761 & 0.096 & -0.148 & 0.088 \\
\hline \multirow{2}{*}{$\begin{array}{l}\text { Lack of social } \\
\text { morality }\end{array}$} & $\begin{array}{c}\text { Assume that the } \\
\text { variances are equal }\end{array}$ & 3.689 & 0.057 & -1.126 & 122 & 0.262 & -0.101 & 0.090 \\
\hline & $\begin{array}{l}\text { Assume that the } \\
\text { variances are not equal }\end{array}$ & & & -1.110 & 90.379 & 0.270 & -0.101 & 0.091 \\
\hline \multirow{2}{*}{$\begin{array}{l}\text { Waste of } \\
\text { resources }\end{array}$} & $\begin{array}{l}\text { Assume that the } \\
\text { variances are equal }\end{array}$ & 3.315 & 0.071 & -0.869 & 122 & 0.387 & -0.076 & 0.088 \\
\hline & $\begin{array}{l}\text { Assume that the } \\
\text { variances are not equal }\end{array}$ & & & -0.882 & 99.033 & 0.380 & -0.076 & 0.087 \\
\hline \multirow{2}{*}{ safe question } & $\begin{array}{l}\text { Assume that the } \\
\text { variances are equal }\end{array}$ & 0.292 & 0.590 & 0.316 & 122 & 0.752 & 0.030 & 0.093 \\
\hline & $\begin{array}{l}\text { Assume that the } \\
\text { variances are not equal }\end{array}$ & & & 0.316 & 93.839 & 0.753 & 0.030 & 0.094 \\
\hline
\end{tabular}


Using software to test the factors affecting the use of urban bicycles in Linfen City, the $\mathrm{KMO}$ test coefficient is 0.554 , greater than 0.5 , and the Bartlett spherical test $p$ value is 0.001 , less than 0.05 , which indicates that the correlation between variables is very strong, and factor analysis can be done. Factor analysis is carried out for 10 independent variables, mainly using principal component analysis to extract factors, and then using the maximum equilibrium value method for factor rotation. As a result, four dimensions were extracted. The eigenvalues of the four dimensions were 1.751, 1.291, 1.124, and 1.082, respectively. The cumulative explanatory variation is $52.447 \%$, combined with the results of KMO test coefficient and the Bartlett spherical test $p$, to some extent, the variables extracted using factor analysis represents the original variables.

The converted variables are classified, the cycling comfort and the scope of application are labeled as "hardware service", and the convenience of returning the bike is separately labeled as "software service". The procedures and usage fees are labeled as "operational services", and the remaining congregational psychology, green environmental protection, lack of social morality, waste of resources and safety issues are labeled as "customer perception" (Table 4). When building the usage impact factor model, the above four dimensions will be used as independent variables.

Table 4. Factor Analysis Results-Rotation Component Matrix.

\begin{tabular}{|c|c|c|c|c|}
\hline & \multicolumn{4}{|c|}{ Ingredients } \\
\hline & Hardware Service & Software Service & Operational Service & Customer Perception \\
\hline Handle procedures & & & 0.206 & \\
\hline Bicycle convenience & & 0.088 & & \\
\hline Use fee & & & -0.244 & \\
\hline Cycling comfort & -0.307 & & & \\
\hline Scope of application & 0.220 & & & \\
\hline Congregational psychology & & & & 0.339 \\
\hline Green & & & & 0.033 \\
\hline Lack of social morality & & & & -0.241 \\
\hline Waste of resources & & & & 0.840 \\
\hline Safe question & & & & -0.070 \\
\hline
\end{tabular}

Note: Extraction method: principal component. Rotation method: full rotation method with Kaiser standardization.

The paper uses "hardware service", "software service", "operational service", and "customer perception" as independent variables, and "daily use" as a reference class to construct an ordered logistic model coefficient (Table 5). As a result, the parallel line test $p=0.797$, far greater than 0.05 , indicates that it is suitable for orderly logistic regression analysis. The $p$ value of the fit is $=0.873$, which is also greater than 0.05 , indicating that the fitting effect of using this model is good.

Table 5. Ordered logistic model.

\begin{tabular}{cccccc}
\hline & & Estimate & Standard Error & Wald & Significant \\
\hline \multirow{3}{*}{ Threshold } & [Cycling frequency = 1] & -0.138 & 0.291 & 0.224 & 0.636 \\
& [Cycling frequency = 2] & 0.877 & 0.302 & 0.428 & 0.004 \\
& [Cycling frequency =3] & 1.445 & 0.321 & 20.300 & 0.000 \\
\multirow{3}{*}{ Position } & Hardware service & 0.370 & 0.368 & 1.014 & 0.314 \\
& Software service & 0.650 & 0.355 & 3.358 & 0.067 \\
& Operational service & -0.173 & 0.360 & 0.231 & 0.631 \\
& Customer perception & -0.052 & 0.488 & 0.011 & 0.916 \\
\hline
\end{tabular}

The hardware service factor has a positive impact on the frequency of public use, which implied that the better the riding comfort is, the wider the scope of application, the more people prefer to use it frequently. The software service factor has the greatest positive impact on the frequency of public use, which means the more convenient the bicycle is, the 
more people are willing to use it. On the contrary, the operational service factors have a negative impact on the frequency of public use, but the impact degree is relatively small. The operational service factors include handling procedures and usage fees, obviously, the complicated processing procedure and the high usage fees will affect the public's willingness, and, in turn, affects the frequency of use of sharing bicycles. Besides, customer perception factors have a negative impact on the frequency of public use, concerns such as security in cycling and the weather will affect the way the public travels, and thus affects the frequency of use.

As far as the feelings of passengers using sharing bicycle were concerned, the preference for interviewees choosing governmental public bicycle or dockless bicycle is different (Table 6). The response rate shows that there is no obvious difference among the respondents in terms of factors such as environment friendliness, sufficient quantity of bicycles, and reasonable distribution of sites. Especially, the common recognition of "environment friendly" is higher than other items, which indicates that most of the public realize the environmental value of sharing bicycles, which is conducive to the promotion of bicycle sharing. On the contrary, there is significant difference among the respondents in terms of easy to borrow and return, easy to handle and pay fee and reasonable usage fee. In particular, compared to dockless bicycles, governmental public bicycles have an advantage in cheaper fees. However, due to the simple procedure and ease of payment, dockless bicycles are more favorable compared to government public bicycles.

Table 6. Comparative analysis of response rate between governmental public bicycle and dockless bicycle.

\begin{tabular}{ccccc}
\hline & \multicolumn{2}{c}{$\begin{array}{l}\text { Governmental } \\
\text { Public Bicycle }\end{array}$} & \multicolumn{2}{c}{ Dockless Bicycle } \\
\cline { 2 - 5 } & $\mathbf{N}$ & Response Rate & $\mathbf{N}$ & Response Rate \\
\hline Sufficient bicycle quantity & 77 & $16.8 \%$ & 82 & $17.9 \%$ \\
Reasonable distribution of sites & 58 & $12.6 \%$ & 77 & $16.8 \%$ \\
Reasonable usage fee & 95 & $20.7 \%$ & 34 & $7.4 \%$ \\
Easy to handle and pay fee & 45 & $9.8 \%$ & 136 & $29.6 \%$ \\
Easy to borrow and return & 92 & $20.0 \%$ & 198 & $43.1 \%$ \\
Environment friendly & 125 & $27.2 \%$ & 134 & $29.2 \%$ \\
\hline
\end{tabular}

\section{Concluding Discussion}

\subsection{Discussion}

Through the questionnaire analysis of the bicycle sharing situation in the Linfen urban area, it is found that both the government public bicycle and dockless bicycle have played a positive role toward public traffic. The benefit is mainly expressed in two aspects: one is to effectively alleviate traffic problems, effectively solve the "last kilometer" problem of travel, and reduce urban environmental pollution [15,16]; the other is to provide a green travel mode, optimize travel structure [17-19], and improve people's environmental literacy. Additionally, the largest sharing bicycle user group is mainly low-income people, who account for $88.23 \%$, while the group with average monthly income over $\$ 784$ only account for $11.76 \%$. It seemed that the higher income earners had less intention to choose sharing bicycles for travel, indicating that sharing bicycles are more important for ordinary citizens than the high-income groups. However, to achieve their energy-saving and emissionreduction goals, the government should try to attract the high-income group to participate in green traffic.

Remarkably, although government public bicycles and dockless bicycles have similarities, there are still many differences. First of all, the main operators are different. The investment and management of dockless bicycles was from the private sector, which are responsible for their own profits and losses. Due to pursuit of profits and market competition, the operators constantly adjust the development strategy to meet the satisfaction of passengers and the needs of society [44]. In contrast, the public bicycles are mainly 
promoted and operated by the local government. However, due to high maintenance and operation costs and limited borrowing and returning regulation of the governmental public bicycle, the local government did not achieve the goal to change citizen traffic behavior. For example, since the Taiyuan Municipal Government introduced public bicycles in 2012, the public financial investment has accumulated $\$ 47.01$ million, with operating costs of $\$ 7.84$ million per year, which has created a heavy financial burden [34]. Secondly, the procedures of bicycle rental and return are different. The procedure of governmental public bicycle rental is tedious. A special IC card is required before bicycle rental, and the bicycle can only be returned to fixed lock piles. At the same time, it is necessary to confirm whether the bicycle is returned to the pile, rental and return procedures are complex and time-consuming. On the contrary, dockless bicycles do not require any magnetic card, users only need to use their mobile phones to scan the QR code of bicycle, and when they have arrived at the destination they can return the bicycle by locking it [11]. However, due to the convenience of bicycle borrowing and returning, they also brought the negative problem of random parking, which, to some extent, aggravated traffic congestion [13]. Finally, the fees are different. The governmental public bicycle can be ridden free for $1 \mathrm{~h}$, and after an hour the charge is 16 cents / hour, while dockless bicycle charges 16 cents for the first $15 \mathrm{~min}$, and then it charges 8 cents $/ 15$ min; therefore, riding for $1 \mathrm{~h}$ costs 40 cents. Obviously, the dockless bicycle is much more expensive, but it supports WeChat, Alipay, and other mobile payment systems which makes it convenient and fast, while the governmental public bicycle must paid by special IC card.

At present, the number of dockless bicycles far exceeds the number of governmental public bicycles all over country. Taking Nanjing City as an example, there are about 415,000 sharing bicycles, of which 98,000 are governmental public bicycles and 317,000 are dockless bicycles [45]. The user market share of governmental public bicycles is consistently shrinking, and the utilization rate has dropped sharply. However, the cost of maintaining the normal operation of the public bicycle system has been significant. Therefore, we cannot help but consider whether the public bicycles should gradually withdrawn and should be completely replaced by dockless bicycles. However, in terms of price and operation management, the public bicycle has a greater social interest value while dockless bicycles have become more and more market-oriented with constantly increasing price. In order to solve the problem of excessive bicycle placement and disorderly management, the government has issued various quotas and assessment measures, but in many cities, the personnel exist for "violent bicycle collection" to combat behavior such as abandonment, dismantling, and even burial of dockless bicycles [21]. Obviously, it is too arbitrary to say "survival of the fittest". The withdrawal of governmental public bicycles often means a dockless bicycle monopoly. At present, the dockless bicycle charges 40 cents for the first hour, while the first hour for the governmental public bicycle is free. In addition, the travel frequency of governmental public bicycles and dockless bicycles is different among different scale cities. The travel frequency of dockless bicycles in Beijing, Shanghai, Hangzhou, and other large cities is higher than that of governmental public bicycles. However, the survey results of Linfen City show that there is no essential difference in the frequency between governmental public bicycles and dockless bicycles in small cities. Therefore, in the future, governmental public bicycles and dockless bicycles should be reasonably allocated according to local conditions and the scale of the city.

At last, the sharing bicycle has had a relatively short operation time in Linfen, and there are still many problems worthy of research and consideration, which have not yet appeared. When issuing the questionnaire, our researchers tried our best to explain the problem where the respondent does not understand, but the information filled by the respondent may still have small errors compared to the actual situation. It is reasonable to consider the results as different in a different scale city; in our future research, more attention should be paid to the adaptation of governmental public bicycles and dockless bicycles, which will conduct comparative studies and increase the empirical research in large cities. 


\subsection{Conclusions}

This paper compares and analyzes the governmental public bicycles and dockless bicycles from three aspects: the purpose of cycling, the frequency of cycling, and the factors affecting cycling. The results show that: (1) The purpose of public cycling is to commute for about $44 \%$ of the study population, which echoes the government's aim to solve the 'last kilometer'. On the one side, the riding of governmental public bicycles to work was the largest proportion, at about $29 \%$, mainly because of the fixed route of travel, and the fixed placement of governmental public bicycles, that are more readily available than the random arbitrariness of dockless bicycle. On the other side, the aim of riding a dockless bicycle for entertainment accounts for the largest proportion, at about $34 \%$, mainly due to the ease of borrowing and returning a bike, and mobile payment. (2) In terms of frequency, the rate of occasional use is up to nearly $70 \%$, and more than $12 \%$ of the study population use sharing bikes almost every day, indicating that bicycle sharing has gained some fans. In addition, the public's choice of riding dockless bicycles or governmental public bikes has no essential differences, given that there are only two options for citizens in Linfen. (3) There are significant differences between government public bicycles and dockless bicycles in four aspects: simple procedures, convenient return, low cost of use, and herd mentality. From the questionnaire analysis, the largest group of sharing bicycle users is mainly low-income people account for $88.23 \%$ in Linfen, so the transportation costs are extremely important to transportation choice; accordingly the response of Linfen residents to the public bike is that the advantage of lower charge, however, the dockless bike has more advantages in procedure to borrow and return the bike.

Based on this, we give some suggestions for the scientific and rational development of sharing bicycles in Linfen City in the future. Firstly, according to Linfen's survey results, when going to work the citizen prefer governmental public bicycle to dockless bicycles, mostly because of the fixed line, point-to-point traffic. Therefore, the Mobike Company can set a fixed route to office areas, schools, hospitals, residential areas to attract more users. Secondly, when a public bicycle requires to buy a bus card at a designated place, this is relatively cumbersome and somewhat off-putting. However, the passenger can use Alipay and Wechat APP to pay the bus ticket by scanning for the QR code. Therefore, the government can try to apply this procedure to improve the utilization rate of public bicycles in the future, by utilizing an electronic bus card on a mobile phone in the borrowing and returning of a bicycle. Thirdly, when returning governmental public bicycles, public bicycle stations must be found, and there are spare piles to return them. However, due to the lack of information on the parking space, cyclists can only find the parking space by luck. Therefore, municipal traffic managers could consider developing a real-time network distribution map of public bicycles in the future, so that cyclists can check the nearest parking spot with a spare space from their mobile phones.

Author Contributions: Conceptualization, X.G. and C.L.; methodology, X.G. and Y.G.; formal analysis, X.G. and C.L.; investigation, X.G., C.L., D.S. and Y.G.; writing-original draft preparation, X.G. and C.L.; writing-review and editing, X.G., C.L. and B.X. All authors have read and agreed to the published version of the manuscript.

Funding: This research was funded by the National Key R\&D Program of China (Grant No. 2018YFC0704702), the Science and Technology Basic Resources Survey Project of China (2017FY101304), Major R\&D Project of Chinese Academy of Sciences (ZDRW-ZS-2016-6-5), National Natural Science Foundation of China (41701142, 41971162, 41471116), Ministry of Education in China Liberal arts and Social Sciences Foundation (20YJC630032), and the Youth Innovation Promotion Association CAS (2016181).

Institutional Review Board Statement: Not applicable.

Informed Consent Statement: Not applicable.

Data Availability Statement: The data used to support the findings of this study are available from the corresponding author upon reasonable request. 
Conflicts of Interest: The authors declare no conflict of interest.

\section{References}

1. Nguyen, T.B.N.; Do, T.L. Some solutions of "Smart city" in response to urban climate change. IOP Conf. Ser. Mater. Sci. Eng. 2020, 869. [CrossRef]

2. Verbavatz, V.; Barthelemy, M. Access to mass rapid transit in OECD urban areas. Sci. Data 2020, 7, 301. [CrossRef]

3. Qiu, L.-Y.; He, L.-Y. Bike Sharing and the Economy, the Environment, and Health-Related Externalities. Sustainability 2018, 10, 1145. [CrossRef]

4. Nikitas, A.; Wallgren, P.; Rexfelt, O. The paradox of public acceptance of bike sharing in Gothenburg. Eng. Sustain. 2016, 169, 101-113. [CrossRef]

5. Thomopoulos, N.; Nikitas, A. Editorial: Smart urban mobility futures. Int. J. Automot. Technol. Manag. 2019, 19, 1-9.

6. Mueller, N.; Rojas-Rueda, D.; Cole-Hunter, T.; de Nazelle, A.; Dons, E.; Gerike, R.; Götschi, T.; Panis, L.I.; Kahlmeier, S.; Nieuwenhuijsen, M. Health impact assessment of active transportation: A systematic review. Prev. Med. 2015, 76, 103-114. [CrossRef]

7. Yang, W.; Li, T.; Cao, X. The Evolution of Spatial-temporal Characteristics and Influence Factors of $\mathrm{CO}_{2}$ Emissions from Transport in China: A Panel Data Analysis of 30 Provinces in China from 2000 to 2012. Sci. Geogr. Sin. 2016, 36, 491-501. [CrossRef]

8. Şimşekoğlu, Ö.; Nordfjærn, T.; Rundmo, T. Predictors of car use habit strength in an urban Norwegian public. Transportation 2017, 44, 575-588. [CrossRef]

9. Buehler, R.; Pucher, J.; Gerike, R.; Götschi, T. Reducing car dependence in the heart of Europe: Lessons from Germany, Austria, and Switzerland. Transp. Rev. 2016, 37, 4-28. [CrossRef]

10. Gärling, T.; Garling, A.; Loukopoulos, P. Forecasting Psychological Consequences of Car Use Reduction: A Challenge to an Environmental Psychology of Transportation. Appl. Psychol. 2002, 51, 90-106. [CrossRef]

11. Si, H.; Shi, J.-G.; Wu, G.; Chen, J.; Zhao, X. Mapping the bike sharing research published from 2010 to 2018: A scientometric review. J. Clean. Prod. 2019, 213, 415-427. [CrossRef]

12. Nikitas, A. How to Save Bike-Sharing: An Evidence-Based Survival Toolkit for Policy-Makers and Mobility Providers. Sustainability 2019, 11, 3206. [CrossRef]

13. DeMaio, M.P. Bike-sharing: History, Impacts, Models of Provision, and Future. J. Public Transp. 2009, 12, 41-56. [CrossRef]

14. Midgley, P. The role of smart bike-sharing systems in urban mobility. Journeys 2009, 2, 23-31.

15. Shaheen, S.; Chan, N. Mobility and the Sharing Economy: Potential to Facilitate the First- and Last-Mile Public Transit Connections. Built Environ. 2016, 42, 573-588. [CrossRef]

16. Audikana, A.; Ravalet, E.; Baranger, V.; Kaufmann, V. Implementing bikesharing systems in small cities: Evidence from the Swiss experience. Transp. Policy 2017, 55, 18-28. [CrossRef]

17. Yang, J.; Liu, Y.; Liu, M.; Bi, J. The Challenges and Countermeasures for City-level Low-carbon Transportation Development in the Internet Era. Environ. Prot. 2018, 46, 43-46. (In Chinese) [CrossRef]

18. Feng, X.; Cai, B. A Review on Policies of Reducing Carbon Emission in China's Urban Road Transport System. China Popul. Resour. Environ. 2012, 8, 10-15. (In Chinese)

19. Zhou, Y.; Zhang, B.; Li, Q. Research Progress and Prospect in the Study of Public Bicycle System. Urban Dev. Stud. 2014, 9 , 118-124. (In Chinese)

20. Lin, C.; Hua, T.; Jiang, Z.; Cheng, S. A Sharing Economy Feast-Take Shared Cycling as an Example; People Daily Press: Beijing, China, 2017; p. 96. (In Chinese)

21. Zhang, Y.; Huang, Z. Performance evaluation of bike sharing system in Wuchang area of Wuhan, China. In Proceedings of the 2012 6th International Association for China Planning Conference (IACP), Wuhan, China, 17-19 June 2012; pp. 1-10.

22. Zhou, Q. High cost of parking and recycling and lack of grass-roots law enforcement based on "violent car collection" made the enterprises helpless and "bicycle graveyard" sequelae investigation. China Econ. Wkly. 2019, 8, 91-93. (In Chinese)

23. Efthymiou, D.; Antoniou, C. Understanding the effects of economic crisis on public transport users' satisfaction and demand. Transp. Policy 2017, 53, 89-97. [CrossRef]

24. Lee, K.H.; Won, D.H.; Ko, E.J. The multiple impacts of the neighbourhood environment on the use of public bicycles by residents: An empirical study of Changwon in Korea. Int. J. Urban Sci. 2015, 19, 224-237. [CrossRef]

25. Bordagaray, M.; Dell'Olio, L.; Ibeas, Á.; Barreda, R.; Alonso, B. Modeling the Service Quality of Public Bicycle Schemes Considering User Heterogeneity. Int. J. Sustain. Transp. 2014, 9, 580-591. [CrossRef]

26. El-Assi, W.; Mahmoud, M.S.; Habib, K.N. Effects of built environment and weather on bike sharing demand: A station level analysis of commercial bike sharing in Toronto. Transportation 2017, 44, 589-613. [CrossRef]

27. Levy, N.; Golani, C.; Ben-Elia, E. An exploratory study of spatial patterns of cycling in Tel Aviv using passively generated bike-sharing data. J. Transp. Geogr. 2019, 76, 325-334. [CrossRef]

28. Radzimski, A.; Dzięcielski, M. Exploring the relationship between bike-sharing and public transport in Poznań, Poland. Transp. Res. Part A Policy Pract. 2021, 145, 189-202. [CrossRef]

29. Caldwell, K.B.; Boyer, R.H.W. Bicycle commuting in an automobile-dominated city: How individuals become and remain bike commuters in Charlotte, North Carolina. Transportation 2018, 46, 1785-1806. [CrossRef]

30. Luo, S.; Zhen, F.; Yin, Q. How Built Environment Influence Public Bicycle Usage: Evidence from the Bicycle Sharing System in Qiaobei Area, Nanjing. Sci. Geogr. Sin. 2018, 38, 332-341. (In Chinese) [CrossRef] 
31. Qian, J.; Wang, D.; Niu, Y. Analysis of the influencing factors of urban residents to use urban public bikes: A case study of Suzhou. Geogr. Res. 2014, 33, 358-371. (In Chinese) [CrossRef]

32. Wan, Y.; Luo, M.; Liu, W. A Study on the Influencing Factors of Using Sharing Bicycles in Urban Recreation-A Case Study of Tianjiling National Forest Park in Hunan Province. J. Cent. South Univ. For. Technol. 2018, 12, 88-94. (In Chinese) [CrossRef]

33. Li, X.; Zhang, Y.; Sun, L.; Liu, Q. Free-Floating Bike Sharing in Jiangsu: Users' Behaviors and Influencing Factors. Energies 2018, 11, 1664. [CrossRef]

34. Liang, Z. Similarities and Differences of Public Bikes and Sharing Bikes. Munic. Eng. Technol. 2017, 35, 31-32. (In Chinese)

35. Lazarus, J.; Pourquier, J.C.; Feng, F.; Hammel, H.; Shaheen, S. Micromobility evolution and expansion: Understanding how docked and dockless bikesharing models complement and compete-A case study of San Francisco. J. Transp. Geogr. 2020, 84, 102620. [CrossRef]

36. Long, L.G.; Gan, Z.; Zhang, D. Investigation on the Characteristics of Sharing bicycle Use in Ximen Area of Beijing. Beijing Plan. Rev. 2017, 5, 81-86. (In Chinese)

37. Chen, M.; Wang, D.; Sun, Y.; Waygood, E.O.D.; Yang, W. A comparison of users' characteristics between station-based bikesharing system and free-floating bikesharing system: Case study in Hangzhou, China. Transportation 2020, 47, 689-704. [CrossRef]

38. Li, X.; Zhang, Y.; Du, M.; Yang, J. Social Factors Influencing the Choice of Bicycle: Difference Analysis among Private Bike, Public Bike Sharing and Free-Floating Bike Sharing in Kunming, China. KSCE J. Civ. Eng. 2019, 23, 2339-2348. [CrossRef]

39. Ji, Y.; Ma, X.; He, M.; Jin, Y.; Yuan, Y. Comparison of usage regularity and its determinants between docked and dockless bike-sharing systems: A case study in Nanjing, China. J. Clean. Prod. 2020, 255, 120110. [CrossRef]

40. Ma, Y.; Jing, L.; Thornton, T.; Mangalagiu, D.; Zhu, D. Challenges of Collaborative Governance in the Sharing Economy: The case of free-floating bike sharing in Shanghai. J. Clean. Prod. 2018, 197, 356-365. [CrossRef]

41. Du, M.; Cheng, L. Better Understanding the Characteristics and Influential Factors of Different Travel Patterns in Free-Floating Bike Sharing: Evidence from Nanjing, China. Sustainability 2018, 10, 1244. [CrossRef]

42. Liu, L.; Li, Y.; Xu, G. Empirical study of bike sharing service satisfactions in Wuhan City. Logist. Eng. Manag. 2011, 5, 31-32. (In Chinese) [CrossRef]

43. Caulfield, B.; O’Mahony, M.; Brazil, W.; Weldon, P. Examining usage patterns of a bike-sharing scheme in a medium sized city. Transp. Res. Part A Policy Pract. 2017, 100, 152-161. [CrossRef]

44. Gu, K.; Zhu, P.; Ning, Y.; Wang, F. Zoning and Regulation of Air Pollution in Hefei City Based on the Concept of Green Travel. Sci. Geogr. Sin. 2019, 39, 1312-1320. [CrossRef]

45. Yangtse Evening Post. Nanjing Dockless Bikes Dropped Sharply while Government Public Bikes Increasing [EB/OL] (18 April 2019). Available online: http://m.xinhuanet.com/js/2019-04/18/c_1124382475.htm (accessed on 18 April 2019). 